\title{
Thymoquinone Suppresses Cell Proliferation and Enhances Apoptosis of HL60 Leukemia Cells through Re-Expression of JAK/STAT Negative Regulators
}

\author{
Belal Almajali ${ }^{1}$, Hamid Ali Nagi Al-Jamal ${ }^{1 *}$, Wan Rohani Wan Taib ${ }^{1}$, Imilia \\ Ismail $^{1}$, Muhammad Farid Johan ${ }^{2}$, Abd Almonem Doolaanea ${ }^{3}$, Wisam Nabeel \\ Ibrahim $^{4}$, Syed Ahmad Tajudin ${ }^{5}$
}

\begin{abstract}
Objective: The natural compound, thymoquinone (TQ) has demonstrated potential anticancer properties in inhibiting cell proliferation and promoting apoptosis in myeloid leukemia cells, breast cancer cells, and others. However, the effect mechanism of TQ on AML cells still not fully understood. In this study, the authors examined the effects of TQ on the expression of JAK/STAT-negative regulator genes SOCS-1, SOCS-3, and SHP-1, and their consequences on cell proliferation and apoptosis in HL60 leukemia cells. Methods: MTT and trypan blue exclusion tests were conducted to determine the $50 \%$ inhibitory concentration (IC50) and cell proliferation. FITC Annexin and Guava ${ }^{\circledR}$ reagent were used to study the cell apoptosis and examine the cell cycle phases, respectively. The expression of JAK/STATnegative regulator genes, SOCS-1, SOCS-3, and SHP-1, was investigated using reverse transcriptase- quantitative PCR (RT-qPCR). Results: TQ demonstrated a potential inhibition of HL60 cell proliferation and a significant increase in apoptotic cells in dose and time-dependent manner. TQ significantly induced cycle arrest at G0-G1 phase $(\mathrm{P}<0.001)$ and enhanced the re-expression of $J A K / S T A T$-negative regulator genes. Conclusion: TQ potentially inhibited HL60 cell proliferation and significantly increased apoptosis with re-expression of JAK/STAT-negative regulator genes suggesting that TQ could be a new therapeutic candidate for leukemia therapy.
\end{abstract}

Keywords: Thymoquinone- leukemia- JAK/STAT signaling- negative regulators

Asian Pac J Cancer Prev, 22 (3), 879-885

\section{Introduction}

Acute myeloid leukemia (AML) is a type of blood cancer characterized by the accumulation of malignant myeloid cells in the bone marrow and blood (Zhou et al., 2016). Up to date, AML patients are treated by intensive chemotherapy. However, besides the high cost of chemotherapy and its side effects, there is a low five-year survival rate in patients of 20 years and older (Sheridan 2017), and 50\% of cases developed resistance (Lucas et al., 2008; Nik et al ., 2010). Therefore, alternative cheap, available, and low side effect treatment option is vitally needed.

Natural compounds are essential sources of new anticancer drugs due to their modulating effects on apoptosis and cell cycle in cancer cells with a harmless impact on healthy cells (Fulda, 2010). Thymoquinone
(TQ) is one of the essential bioactive ingredients in Nigella sativa and has demonstrated potential anticancer properties (Kundu et al., 2014). Several studies have shown that TQ has inhibited cell proliferation and enhanced apoptosis in myeloid leukemia cells (El-Mahdy et al., 2005), breast cancer cells (Yıldırım et al., 2019), and multiple myeloma (Siveen et al., 2014; Li et al., 2010). However, the effect mechanism of TQ on AML cells still not fully understood.

Janus kinase/signal transducer and activator of transcription (JAK/STAT) pathway plays a critical role in cell events and is activated by growth factors and cytokines (Raychaudhuri and Raychaudhuri 2017). Constitutive activation of JAK/STAT signaling pathway promotes the carcinogenesis and contributes to the development of resistance to tyrosine kinase inhibitors in leukemia cells (Al-Jamal et al., 2018). Therefore, JAK/STAT signaling pathway is a promising therapeutic target in

\footnotetext{
${ }^{1}$ School of Biomedicine, Faculty of Health Sciences, Universiti Sultan Zainal Abidin (UniSZA), 20300 Terengganu, Malaysia. ${ }^{2}$ Department of Haematology, School of Medical Sciences, Universiti Sains Malaysia, Kubang Kerian, Kelantan, Malaysia. ${ }^{3}$ Pharmaceutical Technology Department, Faculty of pharmacy, International Islamic University Malaysia, Kuantan, Malaysia. ${ }^{4}$ Department of Biomedical Sciences, Collage of Health sciences, QU Health, Qatar University, Doha, Qatar. ${ }^{5}$ Centralized Laboratory Management Centre, Universiti Sultan Zainal Abidin, 22200 Besut, Terengganu, Malaysia. *ForCorrespondence: aljamalhamid@unisza.edu.my
} 
several cancers, including leukemia (Pencik et al., 2016). $J A K / S T A T$ signaling is negatively regulated by tumor suppressor genes such as protein tyrosine phosphatase (SHP-1) and suppressor of cytokine signal transduction family (SOCS), particularly SOCS-1 and SOCS-3 (Stec et al., 2013: Tabassum et al., 2019). Additionally, JAK/ STAT signaling pathway is constitutively activated due to epigenetic silencing of its negative regulator genes (Beldi-Ferchiou et al., 2017).

The present study aimed to evaluate the effect mechanism of TQ on HL60 leukemia cells. For this purpose, cytotoxicity, apoptosis, cell cycle assays, and gene expression analysis of $J A K / S T A T$-negative regulator genes were performed before and after treating HL60 leukemia cells with TQ.

\section{Materials and Methods}

\section{Reagents}

Thymoquinone (purity $\geq 98 \%$ ) was purchased from Sigma-Aldrich (Munich, Germany). RPMI-1640 (RPMI), $1 \%$ penicillin/streptomycin, and MTT (3-(4, 5-dimethyl thiazol-2yl)-2, 5-diphenyl tetrazolium bromide) were obtained from Nacalai Tesque (Kyoto, Japan). Fetal bovine serum was purchased from Tico Europe (Holland). Trypan blue (0.4\%) was purchased from Sigma Chemicals (St. Louis, Missouri, USA). FITC Annexin V apoptosis detection kit was purchased from BD Bioscience (California, USA). Guava ${ }^{\circledR}$ Cell Cycle Reagent Kit was purchased from Millipore (Germany). ReliaPrep ${ }^{\mathrm{TM}}$ RNA Cell Miniprep System and GoTaq 2-Step RT-qPCR System were purchased from Promega (USA).

\section{Thymoquinone preparation}

Thymoquinone stock solution was prepared in dimethyl sulfoxide (DMSO) as $5 \mathrm{mM}$, then appropriate working solutions were prepared by diluting with complete RPMI-1640 culture medium (DMSO concentration in culture media was $<0.1 \%$ ).

\section{Cell line and growth media}

HL60 leukemia cells were purchased from (Elabscience-Biotech Co. Ltd, Wuhan, China) and sub-cultured in T-25 culture flasks containing RPMI, supplemented with $10 \%$ of fetal bovine serum and $1 \%$ penicillin/streptomycin at a density of $5 \times 10^{4}$ cells $/ \mathrm{mL}$ in a humid incubator with $5 \% \mathrm{CO}_{2}$ at $37^{\circ} \mathrm{C}$. The media is changed every 3 to 4 days to maintain cell nutrition until cells reach $70 \%$ confluence. Then the leukemia cells were sub-cultured with or without treatment according to the experiment design for different assays.

\section{Cytotoxicity assay}

HL60 leukemia cells were seeded in 96-well plates at a density of $2 \times 10^{4}$ viable cells $/ 100 \mu \mathrm{L} /$ well, and treated with $1,2,3,4,5$, and $6 \mu \mathrm{M}$ of TQ. The plate was then incubated in a humidified incubator at $37^{\circ} \mathrm{C}$ with $5 \% \mathrm{CO}_{2}$ for 24,48 , and $72 \mathrm{~h}$. MTT was dissolved to a concentration of $5 \mathrm{mg} / \mathrm{ml}$. Twenty $\mu \mathrm{l}$ MTT solution was transferred to each well to yield a final volume of $220 \mu \mathrm{l} /$ well. Plates were incubated for $4 \mathrm{~h}$ at $37^{\circ} \mathrm{C}$ in $5 \% \mathrm{CO}_{2}$ then supernatants were discarded, and $150 \mu 1$ DMSO was added. Plates were then placed on an orbital shaker for $15 \mathrm{~min}$, and the absorbance was recorded using TECAN Infiniti plate reader (TECAN, Männedorf, Switzerland) at $590 \mathrm{~nm}$. The half maximal inhibitory concentration $\left(\mathrm{IC}_{50}\right)$ values were calculated using GraphPad Prism 8.4.3 (San Diego, California, USA). Each experiment was performed in triplicate.

\section{Viability assay}

Trypan blue dye exclusion test was used to determine the viable HL60 leukemia cells after treatment with serial concentrations of TQ. Briefly, $5 \times 10^{4}$ cells/well were seeded in 6-well plates and incubated with 2,3 , and $4 \mu \mathrm{M}$ TQ in the humidified incubator at $37^{\circ} \mathrm{C}$ with $5 \%$ $\mathrm{CO}_{2}$ for 24,48 , and $72 \mathrm{~h}$. The cells were collected and centrifuged for $5 \mathrm{~min}$ at $500 \mathrm{x} \mathrm{g}$, and resuspended in 200 $\mu l$ phosphate-buffered saline (PBS). Then $10 \mu \mathrm{l}$ of $0.4 \%$ trypan blue was mixed with $10 \mu \mathrm{l}$ cell suspension for manual cells count using a hemocytometer (Hirschmann $\mathrm{GmbH}$, Germany) and an inverted microscope (Olympus, Tokyo, Japan). Each procedure was repeated at least three times.

\section{Apoptosis assay}

FITC Annexin V apoptosis detection kit was used according to the manufacturer's instructions and detected by flow cytometry (Beckman Coulter, Inc., CA, USA) then analyzed by CyExpert software (Beckman Coulter, Inc., CA, USA). Briefly, HL60 leukemia cells were incubated with 1,2 , and $3 \mu \mathrm{M}$ TQ in a 6 -well plate for 24,48 , and $72 \mathrm{~h}$ and washed with phosphate-buffered saline (PBS). Cells were then collected and resuspended in binding buffer (0.1 M Hepes/NaOH (pH 7.4), $1.4 \mathrm{M} \mathrm{NaCl}, 25$ $\mathrm{mM} \mathrm{CaCl}$ ), followed by incubation with FITC Annexin $\mathrm{V}$ and propidium iodide (PI) for $15 \mathrm{~min}$ in dark at room temperature prior to flow cytometric analysis. Each experiment was performed in triplicate.

\section{Cell cycle analysis}

Each phase of the cell cycle was evaluated using DNA flow cytometry analysis. Guava ${ }^{\circledR}$ Cell Cycle Reagent Kit containing propidium iodide was used to determine the cell-cycle phase distributions. The HL60 leukemia cells were treated with 1,2 , and $3 \mu \mathrm{M}$ of TQ for 24,48 , and $72 \mathrm{~h}$, then washed with PBS and fixed with $70 \%$ ethanol for $24 \mathrm{~h}$. The cells were incubated with PI dye for 30 $\min$ at $37^{\circ} \mathrm{C}$. The assay was performed using CytoFLEX Flow Cytometry (Beckman Coulter) according to the manufacturer's instructions and analyzed by CyExpert software (Beckman Coulter). Each experiment was performed in triplicate.

\section{RNA extraction}

Total RNA was extracted from TQ-treated and untreated HL60 leukemia cells after incubation for 48 $\mathrm{h}$ using the ReliaPrep ${ }^{\text {TM }}$ RNA Cell Miniprep System following the manufacturer's instructions. RNA purity and concentration were measured by a NanoPhotometer ${ }^{\circledR}$ NP80 (Implen GmbH, München, Germany). 
Reverse transcription quantitative polymerase chain reaction $(R T-q P C R)$

GoTaq 2-Step RT-qPCR System was used to synthesize cDNA from RNA samples (100 ng) according to the manufacturer's protocol. All PCR amplifications were conducted using $2 \mu \mathrm{l}$ of cDNA in $50 \mu \mathrm{l}$ of GoTaq PCR master mix, following a 2-step amplification protocol: A starting denaturing step for $2 \mathrm{~min}$ at $95^{\circ} \mathrm{C}$, followed by 40 cycles of denaturation for $15 \mathrm{sec}$ at $96^{\circ} \mathrm{C}$, and then annealing and extension for $1 \mathrm{~min}$ at $60^{\circ} \mathrm{C}$ using a StepOne RT-qPCR Systems (Applied Biosystems). Data were analyzed by StepOne Software v2.3 (Applied Biosystems). Beta actin ( $\beta$-actin) was used as a reference gene. The fold changes of gene expression levels were evaluated by relative quantification of 3 target genes, SOCS-1, SOCS-3, and SHP-1 using the $2^{-\Delta \Delta \mathrm{Cq}}$ method (Livak and Schmittgen 2001). The primer sequences are listed in Table 1. All experiments were performed in triplicates.

\section{Statistical analysis}

Kruskal-Wallis and Mann-Whitney tests were conducted for statistical analysis using GraphPad Prism 8.4.3 (San Diego, California, USA) and $\mathrm{P}<0.05$ was considered as significant.

\section{Results}

Thymoquinone potentially inhibits HL60 cell proliferation

To examine the cytotoxicity of TQ on HL60 leukemia cells, the cells were treated with different concentrations of TQ and incubated for 24,48 , and $72 \mathrm{~h}$. The $\mathrm{IC}_{50}$ of TQ on HL60 leukemia cells were $2 \mu \mathrm{M}$ after 24 and $48 \mathrm{~h}$, while it was only $1 \mu \mathrm{M}$ after incubation for $72 \mathrm{~h}$. The results of MTT showed a significant inhibition of viable cells ( $\mathrm{p}<$ 0.001 ) with dose and time-dependent manner (Figure 1A).

Thymoquinone induces apoptosis and cell-cycle arrest at

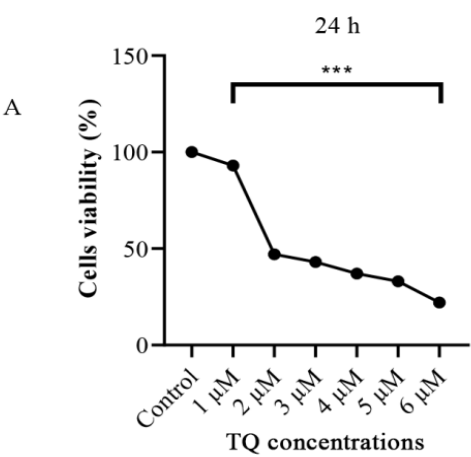

$24 \mathrm{~h}$

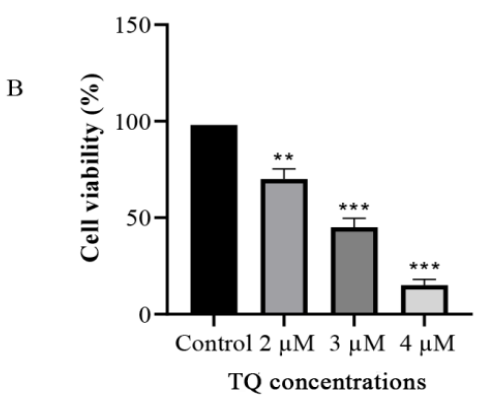

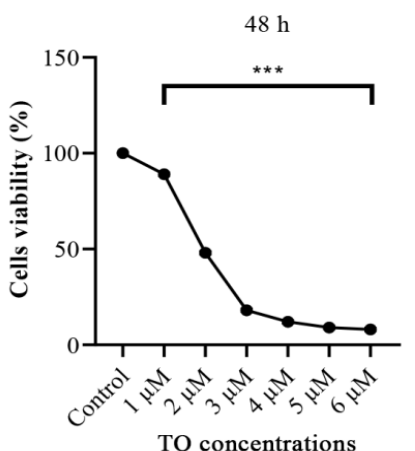

$48 \mathrm{~h}$

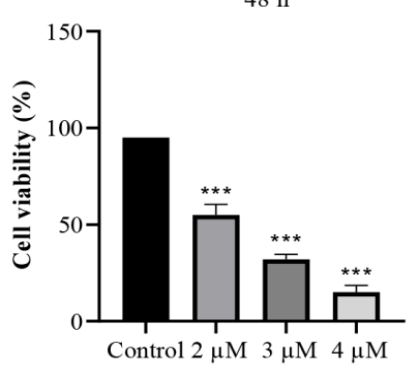

TQ concentrations



TQ concentrations

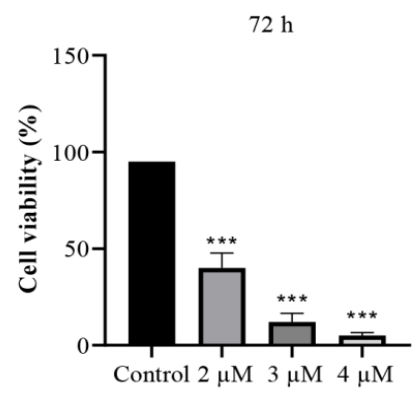

TQ concentrations

Figure 1. TQ Reduces the Viability of HL60 Leukemia Cells. Cytotoxicity of TQ and cell viability were assessed by MTT (A) and trypan blue staining (B) for 24,48 , and $72 \mathrm{~h}$. The IC50 were 2, 2, and $1 \mu \mathrm{M}$, respectively. The increase in dose concentrations directly relates to the inhibition of HL60 leukemia cells. The values are expressed as mean \pm SEM. Experiments were repeated at least three times. $* * p<0.002$ and $* * * p<0.001$ indicated statistical significance.

Table 1. Nucleotide Sequences of the Primers Used in RT-qPCR Study

\begin{tabular}{llll}
\hline Gene & Primer name & Nucleotide sequence $\left(5^{\prime}-3^{\prime}\right)$ & Reference \\
\hline SOCS1 & SOCS1 F & GACGCCTGCGGATTCTAC & Hadroj et al., 2018 \\
& SOCS1 R & AGCGGCCGGCCTGAAAG & \\
SOCS3 & SOCS3 F & GACCAGCGCCACTTCTTCAC & Musalli et al., 2019 \\
& SOCS3 R & CTGGATGCGCAGGTTCTTG & \\
SHP-1 & SHP-1 F & GCCTGGACTGTGACATTGAC & Samarghandian et al., 2019 \\
& SHP-1 R & ATGTTCCCGTACTCCGACTC & \\
$\beta$-actin & $\beta$-actin F & CTGGCACCCAGGACAATG & Relles et al., 2016 \\
& $\beta$-actin R & GCCGATCCACACGGAGTA & \\
\hline
\end{tabular}


A
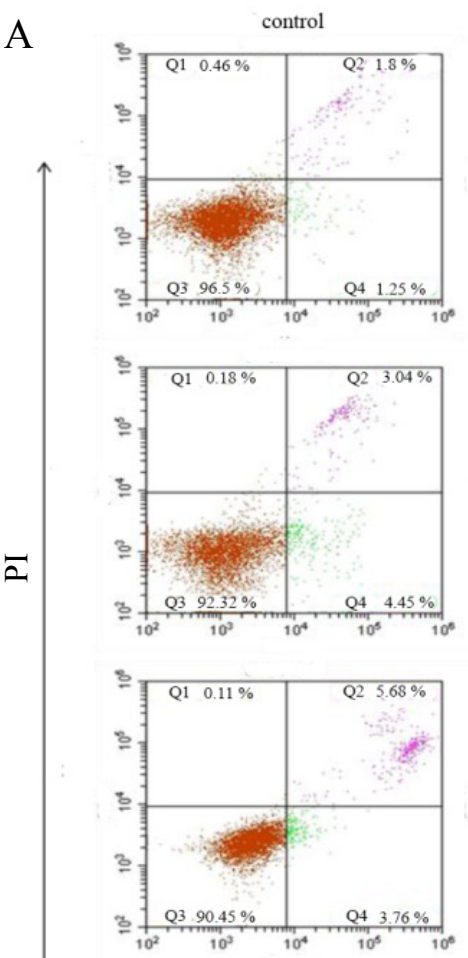
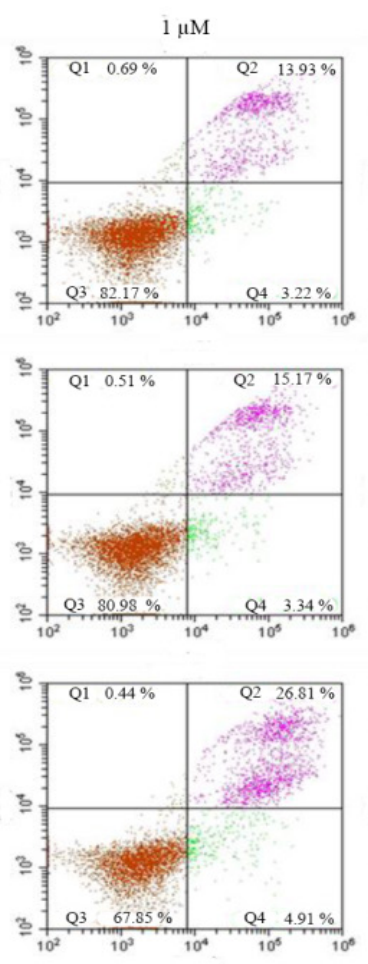
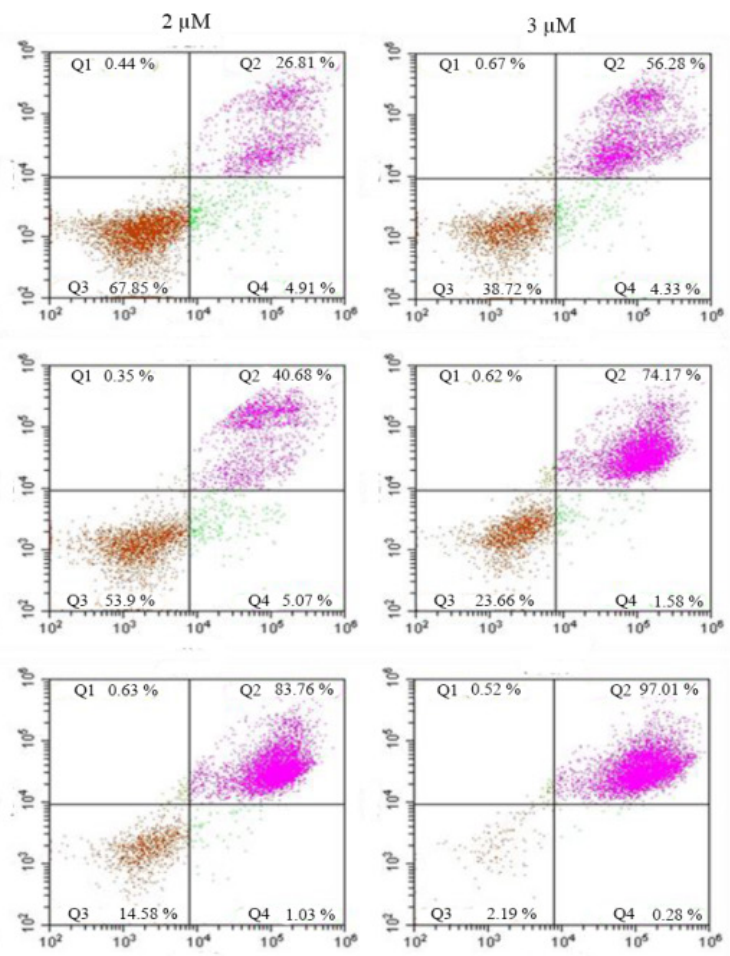
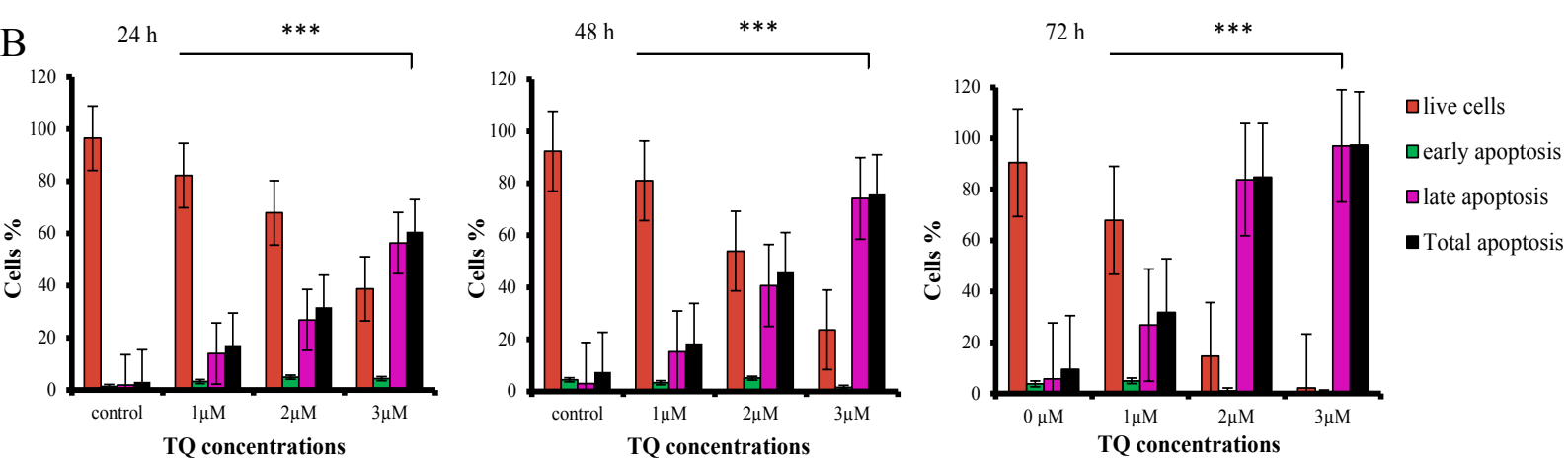

Figure 2. Effectiveness of TQ on HL60 Leukemia Cells Apoptosis. The apoptotic activity of HL60 leukemia cells after treatment with 1,2, and $3 \mu \mathrm{M}$ of TQ for 24, 48, and $72 \mathrm{~h}$. Cells were stained by FITC Annexin V and PI and analyzed by flow cytometry (A). The percentage of cell death based on the estimation of apoptosis in different treatments (B). Time and dose-dependent increase in apoptotic activity was observed. Data were presented as mean $\pm \mathrm{SEM}$. $(\mathrm{p}<0.001)$.

\section{the G1/S Phase}

The vitality and fraction of apoptotic and necrotic HL60 leukemia cells were obtained by FITC annexin $\mathrm{V}$ and flow cytometry analysis (Figure 2). Based on the incubation of cells with 1,2 , and $3 \mu \mathrm{M} \mathrm{TQ}$ for 24,48 , and $72 \mathrm{~h}$, there was a significant reduction of cell viability at all TQ concentrations for all incubation periods compared to that of untreated HL60 leukemia cells. The result revealed that after cells incubation with $1 \mu \mathrm{M} \mathrm{TQ}$, the apoptotic cells were significantly increased (14\%) compared to that in untreated cells (2\%). By increasing TQ concentration, there was a dramatically increased in apoptosis to reached $56 \%, 74 \%$ and $97 \%$ at $3 \mu \mathrm{M}$ after incubation for 24,48 and $72 \mathrm{~h}$, respectively.

The effect of TQ on cell cycle progression of HL60 leukemia cells was investigated after incubation with 1 , 2 , and $3 \mu \mathrm{M}$ TQ for 24,48 , and $72 \mathrm{~h}$. The results showed a significant increase in $\mathrm{G} 0-\mathrm{G} 1$ and $\mathrm{S}$ phase by increasing
TQ concentration with the highest percentages, $53 \%$ and $36 \%$ for G0-G1 and S phase, respectively at $3 \mu \mathrm{M}$ TQ for $72 \mathrm{~h}$ (Figure 3). However, the percentage of cells in G2-M phase was markedly reduced by increasing TQ doses.

Thymoquinone enhances re-expression of JAK/STATnegative regulators

The results revealed a significant up-regulation of SOCS- 1 and SOCS- 3 by a two-fold change compared to untreated cells, while SHP-1 was upregulated for more than three-fold change (Figure 4). These results indicated that TQ effectively re-expressed JAK/STAT-negative regulators.

\section{Discussion}

Up to date, the standard treatment of several cancers including AML is chemotherapy. However, the side effects of chemotherapy and its relapse represent the significant 
A
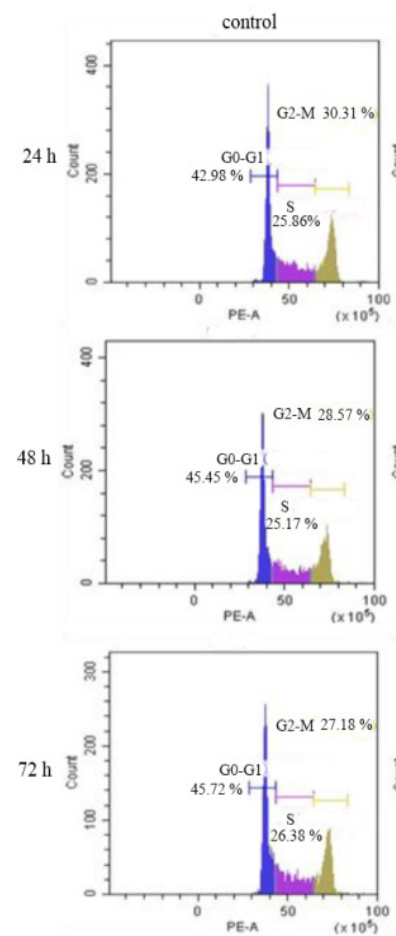

$\mathrm{B}$

$24 \mathrm{~h}$

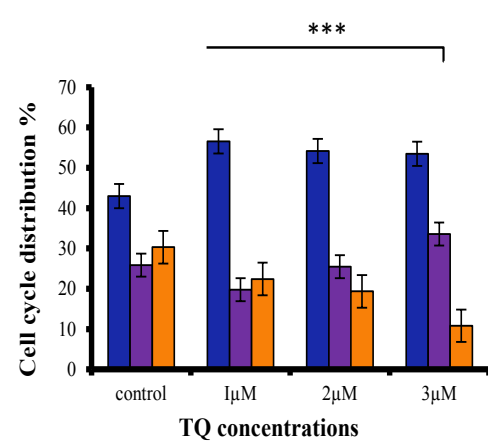

$48 \mathrm{~h}$

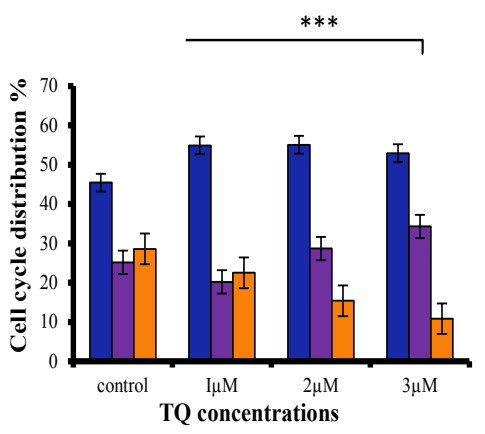

$72 \mathrm{~h}$

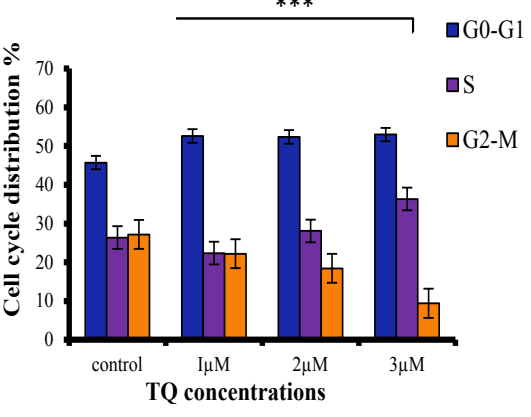

Figure 3. The Cell Cycle Distribution of HL60 Leukemia Cells after Treatment with TQ. Flow cytometric analysis of cell cycle changes after exposure to 1,2 , and $3 \mu \mathrm{M}$ of TQ for 24,48 , and $72 \mathrm{~h}$. The distribution of the cells was determined using flow Cytometry (A). The percentage of cells in different stages of the cell cycle with respect to control (B). Data were presented as mean \pm SEM. $(p<0.001)$.

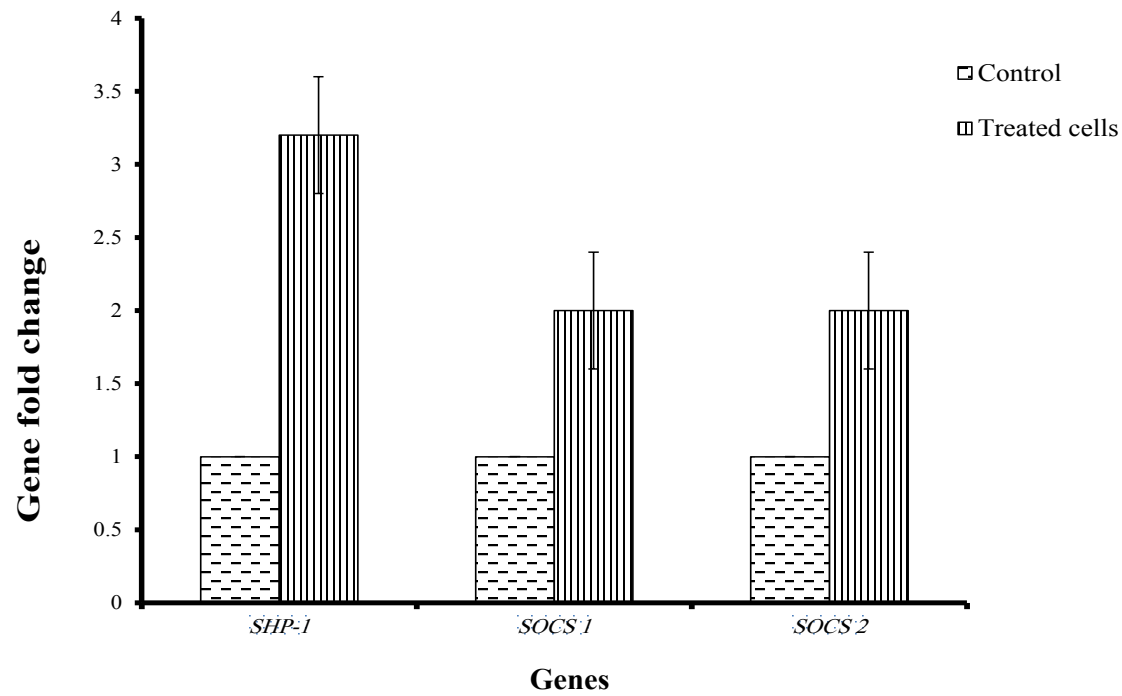

Figure 4. RT-qPCR of Negative Regulators of JAK/STAT Signaling in HL60 Leukemia Cells. The relative normalized ratio of RT-qPCR revealed that TQ significantly up-regulates the expression of targeted genes in treated cells. SHP-1 is re-expressed in treated cells more than 3 fold, while SOCS1 and SOCS3 are re-expressed 2-fold higher compared with control. Data were presented as mean \pm SEM. $(\mathrm{p}<0.001)$. 
challenges in the treatment of AML patients. Therefore, searching for alternative safer, cheaper, more effective and available treatment is crucially needed. TQ has inhibited cell proliferation and enhances apoptosis in many cancers cells, including AML cells (Hodroj et al., 2018; Musalli et al., 2019). In the present study, the effect of TQ on the expression of JAK/STAT-negative regulator genes in HL60 leukemia cells was evaluated.

The $\mathrm{IC}_{50}$ of TQ on HL60 leukemia cells was $2 \mu \mathrm{M}$ after 24 and $48 \mathrm{~h}$ of incubation with TQ but it was only 1 $\mu \mathrm{M}$ after $72 \mathrm{~h}$. Our findings agreed with that previously reported in which the IC50 of TQ on A549 lung cancer cells was determined after exposure for $72 \mathrm{~h}$ and was significantly decreased compared to $24 \mathrm{~h}$ of cell exposure to TQ (Samarghandian et al., 2019). The proliferation of Mia PaCa-2 human pancreatic cancer cells was notably inhibited by increasing TQ concentration and prolonged exposure with the highest inhibition of the cell proliferation at $50 \mu \mathrm{M}$ for $72 \mathrm{~h}$ of exposure compared to 24 and $48 \mathrm{~h}$ (Relles et al., 2016). In similarity, the proliferation assay results of the present study showed a decline in living HL60 leukemia cells after treatment with $1 \mu \mathrm{M}$ TQ to be $93 \%$ compared to only $23 \%$ viable cells after treatment with $6 \mu \mathrm{M}$ TQ for $24 \mathrm{~h}$. On the other hand, the percentages of viable HL60 leukemia cells were significantly decreased to 10,8 and $7 \%$ after incubation for $72 \mathrm{~h}$ compared to 47,44 and $38 \%$, respectively after $24 \mathrm{~h}$ for the same concentrations of TQ $(2,3,4 \mu \mathrm{M})$ suggesting that the effect of TQ on proliferation of HL60 leukemia cells is time and dose-dependent.

Additionally, the expression of JAK/STAT-negative regulator genes, $S H P-1$, SOCS-1, and SOCS-3 genes, was investigated before and after treating HL60 leukemia cells with TQ. Interestingly, the findings of the present study showed that the inhibition of HL60 cell proliferation was associated with re-expression of SHP1, SOCS-1, and SOCS-3 genes that function as tumor suppressor genes through negative regulation of $J A K /$ STAT pathway (Al-Jamal et al., 2018; Wonganan et al., 2017). Our findings are supported by previous findings in which cell proliferation inhibition of breast cancer cells was associated with upregulation of P53 tumor suppressor gene after treatment with TQ (Dastjerdi et al., 2016). Moreover, re-expression of SHP-1, JAK/STAT-negative regulator gene was associated with suppression of STAT3 signaling and cell proliferation inhibition (Al-Jamal et al., 2015). SOCS-1 and SOCS-3 genes are also negative regulators of $J A K / S T A T$ pathway, were down-regulated in MV4-11 leukemia cells and their re-expression by demethylation was associated with inhibition of JAK/ STAT signaling and lower cell proliferation (Al-Jamal et al., 2015). In similarity, our findings revealed that the cell proliferation inhibition of HL60 leukemia cells was associated with a significant re-expression of SHP-1, SOCS-1, and SOCS-3 genes after exposure to $2 \mu \mathrm{M}$ TQ. These findings suggest that TQ inhibited cell proliferation through re-expression of $J A K / S T A T$-negative regulators resulting in inhibition of $J A K / S T A T$ signaling.

Besides, the effect of TQ on HL60 cell apoptosis was assessed in the present study and the results showed that TQ effectively induced apoptosis with a significant increase in the apoptotic cells by increasing the dose of TQ in all exposure periods. The highest apoptosis was detected after $72 \mathrm{~h}$ of exposure (97\%) compared to $56 \%$ and $74 \%$ apoptotic cells after 24 and $48 \mathrm{~h}$ respectively, with the same TQ concentration. These findings suggest that the effect of TQ on apoptosis in HL60 leukemia cells is time and dose-dependent. These results were similar to that reported by Amin Soltani and colleagues (Soltani, et al., 2017) in which TQ enhanced apoptosis in Jurkat leukemia cells with time and dose-dependent manner.

Furthermore, TQ showed anti-proliferative activity by inducing cell-cycle arrest at the G0/G1 and S phase associated with re-expression of the tumor suppressor protein (Gali-Muhtasib et al., 2008; Al-Jamal et al., 2018). In consistency, the findings of the present study indicate that TQ induced cell cycle arrest of HL60 leukemia cells at $\mathrm{G} 1$ and $\mathrm{S}$ phases that were $46 \%$ and $27 \%$, respectively before treatment and increased significantly to become $53 \%$ and $37 \%$ after treatment with $3 \mu \mathrm{M}$ TQ for the same period of incubation. The results also showed that TQ induced HL60 cell cycle arrest at S phase in time and dose-dependent manner.

Taken together, the findings of the present study indicate that TQ induced cell proliferation inhibition of HL60 leukemia cells with a cell cycle arrest in early stages, and apoptosis induction associated with re-expression of SHP-1, SOCS-1, and SOCS-3 genes. The findings suggest that the effect of TQ on apoptosis and cell cycle-arrest of HL60 leukemia cells could be due to the suppression of JAK/STAT signaling through enhanced re-expression of JAK/STAT-negative regulators. However, further study is needed to investigate the TQ effect on JAK/STAT signaling.

\section{Author Contribution Statement}

Conceptualization, H.A. and B.A.; methodology, B.A., H.A.; software, B.A., H.A., S.J.; validation, H.A., A.D. and W.I.; formal analysis, B.A.; investigation, B.A., H.A.; resources, H.A.; data curation, B.A.; writing —original draft preparation, H.A. and B.A.; writing-review and editing, H.A., A.D., W.I., M.J., W.T., I.I.; visualization, H.A., B.A.; supervision, H.A.; project administration, H.A.; funding acquisition, H.A. All authors have read and agreed to the published version of the manuscript.

\section{Acknowledgements}

The authors would like to thank the all staff in Cell Culture Laboratory of Medical School, Universiti Sultan Zainal Abidin (UniSZA) and International Islamic University Malaysia (IIUM) for their cooperation.

\section{Funding Statement}

This work was funded by the Fundamental Research Grant Scheme of the Ministry of Education, Malaysia [FRGS/1/2019/SKK08/UNISZA/02/3 (RR330)].

Statement conflict of Interest

The authors have no conflicts of interest. 


\section{References}

Al-Jamal HAN, Johan MF, Mat Jusoh SA, et al (2018). Re-expression of bone marrow proteoglycan-2 by 5 -azacytidine is associated with STAT3 inactivation and sensitivity response to imatinib in resistant CML cells. Asian Pac J Cancer Prev, 19, 1585-90.

Al-Jamal HAN, Mat Jusoh SA, Hassan R, et al (2015). Enhancing SHP-1 expression with 5-azacytidine may inhibit STAT3 activation and confer sensitivity in lestaurtinib (CEP-701)resistant FLT3-ITD positive acute myeloid leukemia. $B M C$ Cancer, 15, 869.

Beldi-Ferchiou A, Skouri N, Ben Ali C, et al (2017). Abnormal repression of SHP-1, SHP-2 and SOCS-1 transcription sustains the activation of the JAK/STAT3 pathway and the progression of the disease in multiple myeloma. PLoS One, 12, 0174835 .

Dastjerdi MN, Mehdiabady EM, Iranpour FG, et al (2016). Effect of thymoquinone on P53 gene expression and consequence apoptosis in breast cancer cell line. Int J Prev Med, 7, 66.

El-Mahdy MA, Zhu Q, Wang Q-E, et al (2005). Thymoquinone induces apoptosis through activation of caspase- 8 and mitochondrial events in p53-null myeloblastic leukemia HL-60 cells. Int J Cancer, 117, 409-417.

Fulda S (2010). Modulation of apoptosis by natural products for cancer therapy. Planta Med, 76, 1075-9.

Gali-Muhtasib H, Kuester D, Mawrin C, et al (2008). Thymoquinone triggers inactivation of the stress response pathway sensor CHEK1 and contributes to apoptosis in colorectal cancer cells. Cancer Res, 68, 5609-18.

Hodroj MH, Jardaly A, Abi Raad S, et al (2018). Andrographolide potentiates the antitumor effect of topotecan in acute myeloid leukemia cells through an intrinsic apoptotic pathway. Cancer Manag Res, 10, 1079-88.

Kundu J, Choi BY, Jeong C-H, et al (2014). Thymoquinone induces apoptosis in human colon cancer HCT116 cells through inactivation of STAT3 by blocking JAK2- and Src mediated phosphorylation of EGF receptor tyrosine kinase. Oncol Rep, 32, 821-8.

Livak and Schmittgen (2001). Analysis of relative gene expression data using real-time quantitative PCR and the $2^{-\Delta \Delta \mathrm{Cq}}$ method. Methods, 25, 402-8.

Lucas CM, Wang L, Austin GM, et al (2008). A population study of imatinib in chronic myeloid leukaemia demonstrates lower efficacy than in clinical trials. Leukemia, 22, 1963-6.

Musalli MG, Hassan MA, Sheikh RA, et al (2019). Thymoquinone induces cell proliferation inhibition and apoptosis in acute myeloid leukemia cells: Role of apoptosis-related WT1 and BCL2 genes. Eur J Cell Sci, 1, 2-9.

Nik Man NM, Hassan R, Ang CY, et al (2015). Antileukemic effect of tualang honey on acute and chronic leukemia cell lines. Bio Med Res Int, 2015, 307094.

Pencik J, Pham HTT, Schmoellerl J, et al (2016). JAK-STAT signaling in cancer: From cytokines to non-coding genome. Cytokine, 87, 26-36.

Raychaudhuri SK, Raychaudhuri SP (2017). Janus kinase/ signal transducer and activator of transcription pathways in spondyloarthritis. Curr Opin Rheumatol, 29, 311-6.

Relles D, Chipitsyna GI, Gong Q, et al (2016). Thymoquinone promotes pancreatic cancer cell death and reduction of tumor size through combined inhibition of histone deacetylation and induction of histone acetylation. Adv Prev Med, 2016, 1407840.

Samarghandian S, Azimi-Nezhad M, Farkhondeh T (2019). Thymoquinone-induced antitumor and apoptosis in human lung adenocarcinoma cells. $J$ Cell Physiol, 234, 10421-31.
Sheridan C (2017). First new drug approval for AML in 15 years. Nature, 2017.

Siveen KS, Mustafa N, Li F, et al (2014). Thymoquinone overcomes chemoresistance and enhances the anticancer effects of bortezomib through abrogation of NF- $\mathrm{kB}$ regulated gene products in multiple myeloma xenograft mouse model. Oncotarget, 5, 634-8.

Soltani A, Pourgheysari B, Shirzad h, Sourani Z (2017). Antiproliferative and apoptosis-inducing activities of thymoquinone in lymphoblastic leukemia cell line. Indian $J$ Hematol Blood Transfus, 33, 516-24.

Stec W, Vidal O, Zeidler MP (2013). Drosophila SOCS36E negatively regulates JAK/STAT pathway signaling via two separable mechanisms. Mol Biol Cell, 24, 3000-9.

Tabassum S, Abbasi R, Ahmad N, et al (2019.) Targeting of JAKSTAT Signaling in Breast Cancer: Therapeutic Strategies to Overcome Drug Resistance Breast Cancer Metastasis and Drug Resistance. Springer, pp 271-81.

Wonganan O, He Y, Shen X, et al (2017). 6-Hydroxy-3-Omethyl-kaempferol 6-O-glucopyranoside potentiates the anti-proliferative effect of interferon $\alpha / \beta$ by promoting activation of the JAK/STAT signaling by inhibiting SOCS3 in hepatocellular carcinoma cells. Toxicol Appl Pharmacol, 336, 31-9.

Y1ldırım İH, Azzawri AA, Duran T (2019). Thymoquinone induces apoptosis via targeting the Bax/BAD and $\mathrm{Bcl}-2$ pathway in breast cancer cells. Dicle Tip Derg, 46, 411-7.

Zhou H-S, Carter BZ, Andreeff M (2016). Bone marrow niche-mediated survival of leukemia stem cells in acute myeloid leukemia: Yin and Yang. Cancer Biol Med, 13, 248-59.

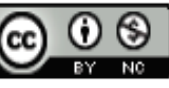

This work is licensed under a Creative Commons AttributionNon Commercial 4.0 International License. 